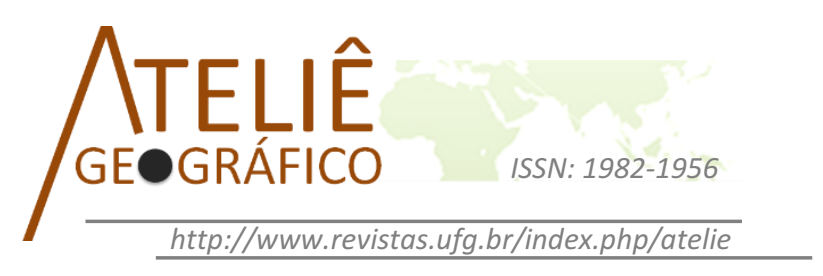

\title{
As unidades de paisagem, as vertentes características e os sistemas pedológicos na bacia hidrográfica do Paraná 3
}

\author{
The landscape units, the characteristic slopes and the \\ pedologic systems in the Paraná watershed 3

\section{Las unidades de paisaje, las laderas características y los sistemas pedológicos en la cuenca de Paraná 3}

\author{
Anderson Sandro da Rocha \\ Universidade Tecnológica Federal do Paraná \\ andersonrocha@utfpr.edu.br \\ Maria Teresa de Nóbrega \\ Universidade Estadual de Maringá \\ mtnobrega@uol.com.br \\ José Edézio da Cunha \\ Universidade Estadual do Oeste do Paraná \\ edeziocunha@hotmail.com
}

\begin{abstract}
Resumo
O presente trabalho tem como objetivo a identificação e detalhamento das vertentes características e dos sistemas pedológicos dominantes nas principais unidades de paisagem da Bacia Hidrográfica do Paraná 3, seguindo os preceitos teóricos e metodológicos da análise estrutural da cobertura pedológica e da análise integrada da paisagem. Foram desenvolvidos trabalhos de gabinete envolvendo a elaboração de cartas temáticas (geologia, clima, declividade, hipsometria, curvatura vertical e solos), trabalhos de campo (levantamento topográfico e pedológico) e laboratório (análises físicas e químicas de solos), que permitiram compreender a estrutura geoecológica e as relações morfopedológicas nos setores alto, médio e baixo da unidade hidrográfica em estudo. No alto setor as vertentes apresentam morfologias convexo-retilíneas e dois sistemas pedológicos dominantes, constituídos por Latossolo Vermelho - Neossolo Regolítico Latossolo Vermelho e Latossolo Vermelho - Nitossolo Vermelho. No setor médio predominam as vertentes convexo-côncavo-retilíneas e o sistema pedológico formado pelo Neossolo Litólico - Nitossolo Vermelho. No setor baixo, às margens do Rio Paraná, dominam formas de vertentes retilíneas com sistema pedológico tipicamente composto pelo Latossolo Vermelho - Nitossolo Vermelho.

Palavras-chave: solos, morfopedologia, unidades de paisagem.
\end{abstract}




\begin{abstract}
The present work has the objective of identifying and detailing the characteristic slopes and dominant pedological systems in the main landscape units of the Paraná watershed 3, following the theoretical and methodological precepts of the structural analysis of the pedological cover and integrated analysis of the landscape. Cabinet work was developed involving the elaboration of thematic maps (geology, climate, declivity, hypsometry, vertical curvature and soils), field work (topographic and pedological survey) and lab work (physical and chemical analyzes of soils), which permitted the geoecological structure and morphopedological relations in the upper, middle and lower sectors of the hydrographic unit under study. In the upper sector the slopes have convex-rectilinear morphologies and two dominant pedological systems, consisting of Red Latosol Regolithic Neosol - Red Latosol and Red Latosol - Red Nitosol. In the middle sector, the convex-concave-rectilinear slopes predominate and pedological system formed by the Litholic Neosol - Red Nitosol. In the low sector, on the margins of the Paraná River, they dominate forms of straight slopes with pedological system typically composed by Red Latosol - Red Nitosol.

Keywords: soils, morphopedological, landscape units.

Resumen

Este estudio tiene como objetivo identificar y detallar las laderas características y los sistemas pedológicos dominantes en las principales unidades de paisaje de la cuenca del Paraná 3 , siguiendo los principios teóricos y metodológicos de análisis estructural del suelo y análisis integrado paisaje. Se desarrollaron trabajos de gabinete que implica la preparación de mapas temáticos (geología, clima, declividad, hipsometría, curvatura vertical y suelo), trabajos de campo (levantamiento topográfico y pedológico) y de laboratorio (análisis físico y químico de los suelos), lo que nos permitió entender la estructura geoecológica y las relaciones morfopedologicas en los sectores de alta, media y baja de la cuenca hidrográfica en estudio. En las laderas del sector superior tienen morfologías convexa-rectilíneas y dos sistemas pedológicos dominantes compuestos por Ferralsol Rojo - Neosol Regolithic - Ferralsol Rojo y Ferralsol Rojo - Nitisol Rojo. En el sector del medio dominado por laderas convexo-cóncava-rectilíneas y el sistema de pedológico formado por Neosol Litholic - Nitisol Rojo. En el sector inferior, a orillas del río Paraná, las formas dominantes de laderas rectilíneas con sistema pedológico normalmente compuesto por Ferralsol Rojo - Nitisol Rojo.
\end{abstract}

Palabras clave: suelo, morfopedologia, unidades de paisaje.

\title{
Introdução
}

As vertentes características, como denominou Young (1972), são responsáveis pela fisionomia geral do relevo de uma determinada área. Torna-se, desse modo, em um instrumento útil para estudos de detalhe, visando a identificação e compreensão da estrutura e funcionamento de compartimentos de relevo e/ou unidades de paisagem.

Os trabalhos que buscam a identificação e a caracterização das vertentes características e dos sistemas pedológicos na paisagem sempre recorreram à metodologia da análise estrutural da cobertura pedológica que trata da análise bi e tridimensional da cobertura pedológica como forma de abordagem, considerando suas possiblidades de 
sistematização e representação dos atributos morfopedológicos (Vidal Torrado et al., 2005).

Entre as principais pesquisas pioneiras relacionadas a análise estrutural da cobertura pedológica, destacam-se os trabalhos de Boulet et al. (1982), Soubiés e Chauvel (1984), Ruellan (1988), Ruellan e Dosso (1993). Para esses autores, os estudos detalhados dos sistemas pedológicos por meio de topossequência de solos, trouxeram a possibilidade de entender o solo como um conjunto estruturado de horizontes pedológicos, distribuídos no espaço e no tempo, dispostos entre si ao longo das vertentes do topo a jusante.

De acordo com Ruellan e Dosso (1993), a análise estrutural da cobertura pedológica, sistematizada por Boulet et al. (1982), além de contribuir com os estudos de gênese e de evolução desse recurso natural, também auxiliam na compreensão da estrutura e do funcionamento da paisagem, em especial porque favorecem a análise sistêmica do ambiente em diferentes escalas, partindo da organização das partículas até a unidade de paisagem. Conforme os autores, esses estudos, permitem evidenciar quatro tipos de estrutura, correspondente a escalas diferentes de organização da cobertura pedológica: as organizações elementares (como constituintes, agregados, concentrações, vazios, traços de atividade biológica); as assembleias (associação de um certo número de organizações elementares e as relações entre elas); os horizontes (volumes pedológicos mais ou menos paralelos à superfície do terreno, caracterizados por vários tipos de assembleias e suas inter-relações); e os sistemas pedológicos.

De acordo com Queiroz Neto (2002), o conjunto de pesquisas desenvolvidas a partir da década de 1980 no âmbito da análise estrutural, permitiram a realização de estudos muito mais completos e complexos. No contexto brasileiro, os trabalhos pioneiros como os de Fernandes Barros (1986), Castro (1989) e Salomão (1994), contribuíram com informações sobre os sistemas pedológicos em transformação, processos geoquímicos, bem como sobre o comportamento físico-hídrico dos solos, evidenciando sobretudo as diferenciações laterais, principalmente ao longo das encostas.

Nesse sentido, os estudos dessa natureza têm possibilitado compreender de forma detalhada as relações e correlações existentes entre as formas de relevo (declividade, concavidade, convexidade e comprimento das vertentes) e a organização da cobertura pedológica ao longo das principais unidades de paisagem.

No contexto mais recente, pesquisas como as de Motta et al. (2002), Manosso e Nóbrega (2009), Campos et al. (2010), dentre outras, realizadas em diferentes regiões do país, tem empregando sobretudo a análise bidimensional da cobertura pedológica, para juntamente com diversos outros elementos naturais e antrópicos, reconhecer e caracterizar as vertentes típicas e os seus sistemas pedológicos como formas de expressão da estrutura e do funcionamento da paisagem.

A investigação com ênfase nas relações entre as classes de solos e a morfologia das vertentes é também designada como morfopedologia e as unidades espaciais 
caracterizadas por determinados arranjos morfopedológicos são denominadas de "unidades morfopedológicas".

A morfopedologia, de acordo com Castro e Salomão (2000), permite cartografar unidades relativamente homogêneas, produtos da inter-relação entre substrato geológico, relevo e solos, que constituem unidades temporo-espaciais e intrínsecas do meio físico reconhecíveis em médias e grandes escalas. As unidades morfopedológicas definidas com ênfase no comportamento hídrico de vertentes permitem destacar sistemas pedológicos dominantes, caracterizados pelo continuum dos seus horizontes, dispostos vertical e lateralmente do topo à base dos interflúvios (Ribeiro e Salomão, 2003).

Essas pesquisas de cunho morfopedológico, ainda possibilitam extrapolação de informações disponíveis em mapas de solos em qualquer escala, para locais e objetivos mais específicos, implicando a redução de tempo e custo para obtenção de dados ambientais básicos (MOTTA et al., 2002).

Nesta perspectiva, é importante ressaltar que o fato do solo e do relevo constituírem corpos tridimensionais da paisagem, faz com que os pontos de observação e a obtenção de dados sejam estabelecidos a partir de ações conjuntas de gabinete e campo. Em gabinete executam-se as consultas e interpretação de cartas temáticas geológicas, geomorfológicas, pedológicas (padrão de drenagem, estrutura geológica, litologia, padrões macromorfológicos do relevo, dentre outras). Em campo, por sua vez, são realizadas as observações das formas das vertentes como rupturas de declives, sinais de erosão, estado da superfície, dentre outros aspectos (Manfredine et al., 2005).

$\mathrm{Na}$ atualidade, como enfatiza Vidal Torrado et al. (2005), os SIGs vêm permitindo elaborar com rapidez mapas temáticos, fornecendo uma visão geral das relações entre o solo e o relevo. Essas aproximações são especialmente importantes para indicar tendências que possam ser verificadas nos estudos detalhados de vertentes, além de permitirem quantificar facilmente as relações que possam existir entre superfícies geomórficas, solos e substratos geológicos, em uma mesma unidade de paisagem.

Com base nesses pressupostos, o objetivo deste trabalho é apresentar as relações entre os solos e as vertentes características de compartimentos de paisagem da unidade hidrográfica Paraná 3, localizada no Oeste paranaense.

\section{Caracterização da Área de Estudo}

A área de pesquisa corresponde à Bacia hidrográfica do Paraná 3 (BP3), uma das doze unidades hidrográficas do Estado do Paraná, delimitadas pela Secretaria do Meio Ambiente e Recursos Hídricos - SEMA, com o objetivo de gestão, gerenciamento e planejamento ambiental. Está localizada na mesorregião Oeste do Estado do Paraná, entre as latitudes $24^{\circ} 01^{\prime} \mathrm{S}$ e $25^{\circ} 35^{\prime} \mathrm{S}$ e longitudes $53^{\circ} 26^{\prime} \mathrm{W}$ e $54^{\circ} 37^{\prime} \mathrm{W}$ e abrange uma área de aproximadamente $8.000 \mathrm{~km}^{2}$ que abriga, de modo parcial ou total, os territórios de 28 municípios (Figura 01). 


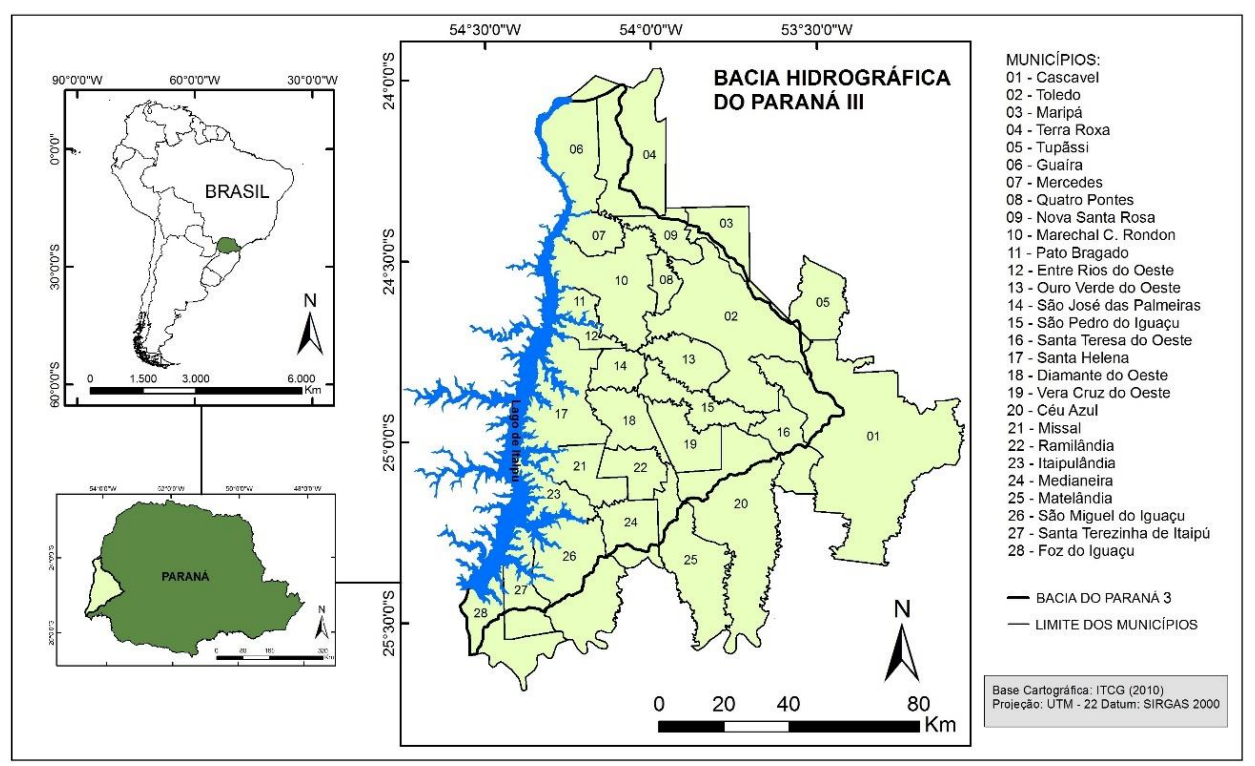

Figura 01. Localização da Bacia Hidrográfica do Paraná III, região Oeste do Paraná.

A BP3 compreende um conjunto de bacias com direcionamento de drenagem de leste para oeste, tributárias do rio Paraná, desaguando diretamente no Reservatório do Lago de Itaipu. A BP3 é subdividida em 12 sub-bacias, abrangendo os cursos principais dos rios Taturi, Chororó, Guaçu, Marreco, São Francisco Verdadeiro, Santa Quitéria, São Francisco Falso Braço Norte, São Francisco Falso Braço Sul, São Vicente, Ocoí, Pinto e Passo-Cuê (Figura 02).

A unidade hidrográfica localiza-se no interior da Bacia Sedimentar do Paraná, no setor Oeste do Terceiro Planalto paranaense, onde o substrato geológico é constituído predominantemente por rochas basálticas da Formação Serra Geral, formadas pelos derrames vulcânicos do período Mesozóico. Ao Norte da bacia, observa-se uma zona de contato entre rochas ígneas efusivas e as rochas sedimentares compostas por arenitos da Formação Caiuá, também do Mesozóico (Mineropar, 2015).

No que se refere a cobertura pedológica, constata-se que as principais classes de solos presentes na área de estudo são compostas por Latossolos Vermelhos Eutroférricos, Latossolos Vermelhos Distroférricos e Nitossolos Vermelhos Eutroférricos em associação com os Neossolos Litólicos e Regolíticos. Os Gleissolos Háplicos e os Organossolos Mésicos também aparecem, mas em pequenas áreas planas e alagadiças, às margens do Rio Paraná (Figura 03). 

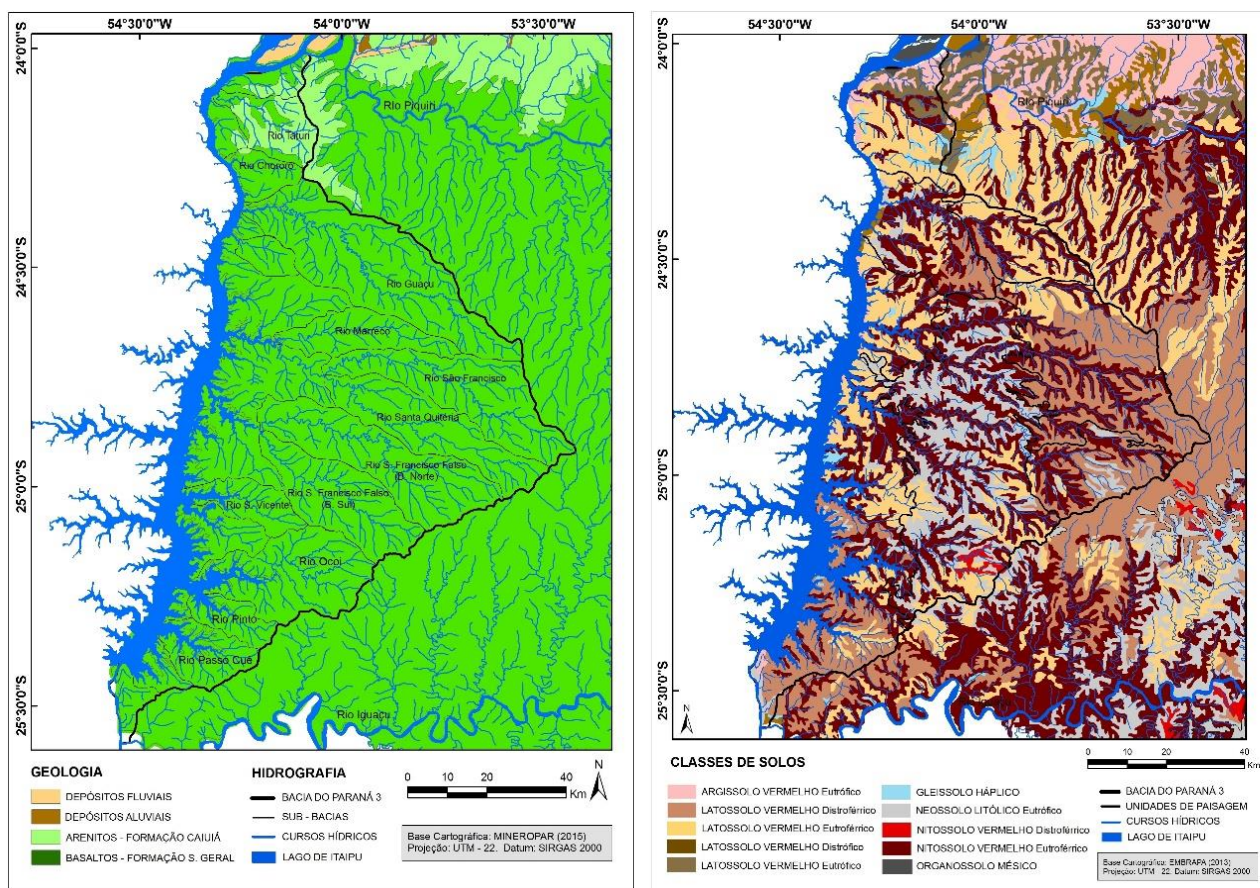

Figura 02. Carta Geológica e Hidrográfica da BP3.

Figura 03. Carta de Solos da BP3.

$\mathrm{Na}$ maior parte área da bacia predominam solos de textura argilosa. Entretanto, ao norte, na zona de contato dos basaltos com os arenitos da Formação Caiuá, ocorre uma pequena mancha de solos de textura média e/ou arenosa, com predominância dos Latossolos e Argissolos Vermelhos.

Apesar do substrato geológico predominantemente basáltico é possível observar importantes variações topográficas e morfológicas (Figuras 04 e 05) que permitem identificar diferentes ambientes geomórficos no setor de superior, no setor intermediário e no setor inferior, localizado às margens do rio Paraná.

O setor de superior (localizado entre as altitudes de 500 e 800 metros) caracteriza-se predominantemente por colinas amplas a médias com topos planos, alongados e vales em $\mathrm{V}$, modelados por vertentes convexo-retilíneas com declividades que variam entre $0-12 \%$. Esse setor representa a frente do interflúvio que delimita a Bacia do rio Paraná 3, e as bacias do rio Iguaçu ao Sul a do Piquiri ao Norte. 


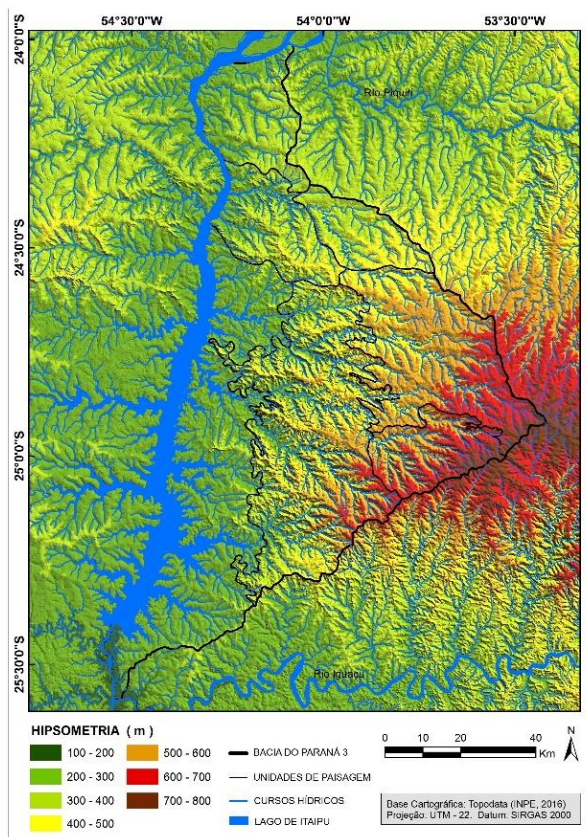

Figura 04. Carta Hipsométrica da BP3.

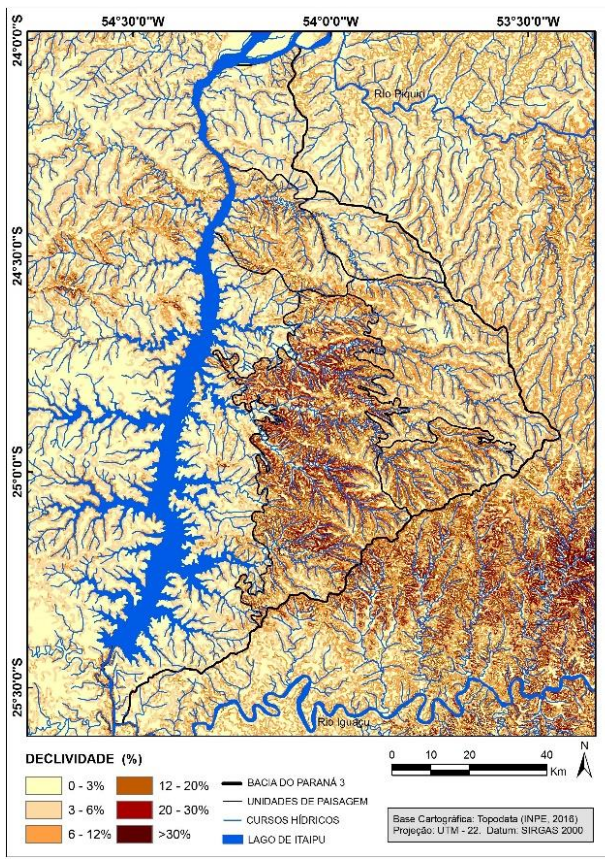

Figura 05. Carta de Declividade da BP3.

O setor intermediário da unidade hidrográfica, onde predominam altitudes entre 300 e 500 metros, situado ao longo dos cursos médios dos rios São Francisco Verdadeiro, Santa Quitéria, São Francisco Falso Braço Norte e Sul, representa o ambiente geomorfológico de maior dissecação da bacia. Esse compartimento exibe espigões estreitos dispostos de Leste para Oeste, modelados pelo encaixe dos cursos principais. As vertentes são convexo-côncavas e convexo-retilíneas, muitas vezes segmentadas em patamares, alternando declividades fracas e muito fortes - entre 6 e $30 \%$. Os topos dos níveis topográficos embutidos entre os espigões principais são curtos e estreitos e os vales em $\mathrm{V}$ e U, conferindo um aspecto geral de relevo amorreado.

O setor inferior da unidade hidrográfica, localizado às margens do rio Paraná entre as 100 e 300 metros de altitude, contempla o ambiente geomorfológico de menor dissecação. É basicamente composto por colinas médias a amplas, topos largos e achatados e vertentes convexo-retilíneas, com declividades muito fracas, predominante entre $0-3 \%$, formando vales em $\mathrm{V}$ muito abertos.

\section{Procedimentos metodológicos}

Os fundamentos teórico-metodológicos utilizadas para compreensão das correlações existentes entre as unidades de paisagem, as vertentes características e os 
sistemas pedológicos dominantes na bacia hidrográfica do Paraná 3, basearam-se nos preceitos da análise integrada da paisagem (Monteiro, 2001) e na análise bidimensional da cobertura pedológica (Boulet et al., 1982). Baseado nesses preceitos foram desenvolvidas duas etapas de trabalho. A primeira contou com a produção de material cartográfico referente elaboração de cartas temáticas, visando a correlação de dados geoambientais. Enquanto que a segunda, contou com trabalhos de levantamentos topográficos e pedológicos, visando a compreensão do comportamento morfopedológico das vertentes características.

\section{Elaboração de cartas temáticas}

A produção de material cartográfico consistiu na elaboração de cartas temáticas (geologia, solos, hipsometria, curvatura vertical, declividade e uso da terra) da área de abrangência da BP3.

Para elaboração da carta geológica foi utilizado, como base cartográfica, o mapa geológico do Paraná (Mineropar, 2015). Já para a elaboração da carta pedológica, foi utilizado a base cartográfica do Levantamento e Reconhecimento dos Solos do Estado, (EMBRAPA, 2008). As informações sobre as formações geológicas e cobertura pedológica foram obtidas na escala de 1:250.000, por meio do site do ITCG (2013), em formato shapefile. As informações foram processadas pelos softwares Global Mapper 15.1 e ArcGis 9.3.

As cartas temáticas geomorfológicas: hipsometria, declividade e curvatura vertical, foram elaboradas a partir dos dados da missão SRTM (Shuttle Radar Topography Mission). Para tanto construiu-se um mosaico a partir das imagens com resolução espacial de $(\sim 30 \mathrm{~m}): 23 \mathrm{~s} 555,23 \mathrm{~s} 54,24 \mathrm{~s} 555,24 \mathrm{~s} 54,25 \mathrm{~s} 555$ e $25 \mathrm{~s} 54$, disponibilizadas pelo Instituto Nacional de Pesquisas Espaciais através do projeto Topodata (INPE, 2013). As informações foram processadas pelo software ArcGis 9.3.

O mapeamento de uso e cobertura da terra da área de estudo foi obtido a partir da análise de imagens do satélite Landsat 8 , com cenas orbitais do ano de 2015, também disponibilizadas pelo INPE (2015). Com a utilização do software ArcGis 9.3, foram geradas as composições coloridas (RGB), utilizando as bandas 4, 5 e 6. Em seguida, utilizou-se a metodologia de classificação supervisionada, por meio do classificador MAXVER (Maximum Likelihood Classification). Esses procedimentos permitiram identificar as classes de vegetação, agricultura, pastagem e corpos hídricos da BP3. Para a identificação detalhada das áreas urbanas, recorreu-se à vetorização manual da imagem RGB.

\section{Levantamentos topográficos e pedológicos}

A análise e correlação das cartas temáticas desenvolvidas na primeira etapa subsidiou a identificação de áreas representativas em termos geomorfopedológicos. 
Nessas áreas, foram desenvolvidos levantamentos de perfis topográficos e estudos pedológicos ao longo das principais unidades de paisagem da bacia do Paraná 3 .

Para o levantamento do perfil topográfico foram analisadas as variações de topografia, morfologia, cobertura pedológica e uso atual das terras. Dessa forma, foram selecionados eixos topográficos típicos (transectos), capazes de evidenciar a forma da vertente e a organização da cobertura pedológica com as suas variações verticais e laterais. O levantamento em campo, com o emprego de clinômetro, metro e trena, possibilitou a elaboração do perfil topográfico dos eixos representativos de vertentes características.

Nessas vertentes, foram desenvolvidos estudos de topossequência de solos. Inicialmente foi realizado o levantamento pedológico prévio, com a execução de sondagens do topo ao sopé da encosta, efetuando-se coletas de amostras de solo a cada $10 \mathrm{~cm}$ de profundidade, utilizando-se do trado holandês. Na sequência realizou-se a análise detalhada das topossequências, com a abertura de trincheiras nos principais segmentos da vertente e/ou nas principais transições, verticais e laterais, verificadas no levantamento pedológico. Nesse processo foram desenvolvidas descrições macro morfológicas (cor, textura, estrutura, consistência, porosidade, atividade biológica, feições pedológicas e transição) dos horizontes pedológicos, seguidas da coleta de amostras deformadas e indeformadas para a realização de análises físicas e químicas, conforme as recomendações de Santos et al. (2005).

\section{Resultados e discussões}

A bacia hidrográfica do Paraná 3 apresenta segundo Bade (2014), cinco grandes compartimentos de paisagem: 1 - Unidade de Cascavel; 2 - Unidade de São Francisco; 3 - Unidade Foz do Iguaçu; 4 - Unidade Marechal Cândido Rondon; 5 - Unidade de Guaíra (Figura 06).

Cada uma dessas unidades se individualiza pela sua estrutura geoecológica (geologia, clima, relevo, solos e vegetação), funcionamento e dinâmica. Essas variações geoambientais se refletem particularmente na organização morfológica do relevo e na composição e distribuição da cobertura pedológica, indicando que as unidades de paisagem identificadas na BP3 também se caracterizam, nessa escala, pelos seus aspectos morfopedológicos.

Nesta perspectiva, foram selecionadas três dessas unidades de paisagem, tomando-se aquelas mais representativas em termos territoriais e morfopedológicos: a unidade de Cascavel, representando o setor mais elevado da área; a unidade de São Francisco, no setor intermediário e a de Foz do Iguaçu, localizada no setor inferior da unidade hidrográfica. Nelas foram identificadas as vertentes características, aquelas cujas formas se repetem espacialmente, contribuindo para a identidade morfológica e dinâmica da unidade de paisagem. 


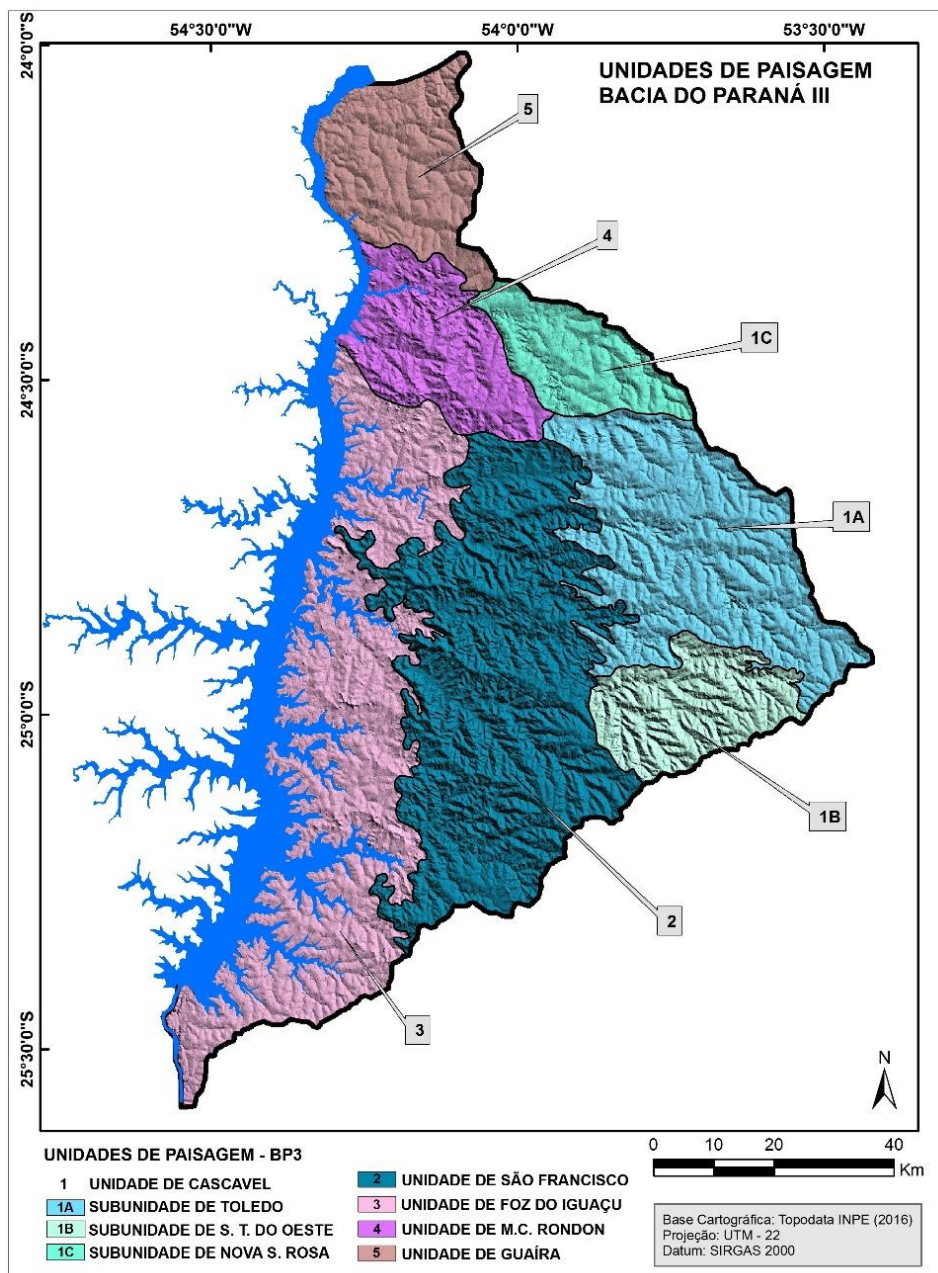

Figura 06. Unidades de Paisagem da BP3.

\section{Unidade de Cascavel: as vertentes características e os sistemas pedológicos no setor de platô}

A unidade de Cascavel localiza-se no Leste da bacia no alto setor da unidade hidrográfica que abriga as cabeceiras dos principais formadores da BP3. Essa grande unidade de paisagem está compartimentada em três subunidades: (1. A) - subunidade de Toledo, (1. B) - subunidade de Santa Teresa do Oeste e (1. C) - subunidade de Nova Santa Rosa. Os sub compartimentos, foram delimitados principalmente pelas diferenças 
nas suas características morfopedológicas (declividade, morfologia das vertentes e solos).

Do ponto de vista geomorfológico, a característica mais representativa ao longo das três subunidades é a presença de colinas amplas a médias, com topos geralmente largos e achatados, vertentes convexo-retilíneas com declividades que variam entre 0 $12 \%$ formando vales em $\mathrm{V}$ abertos (Figura 07).

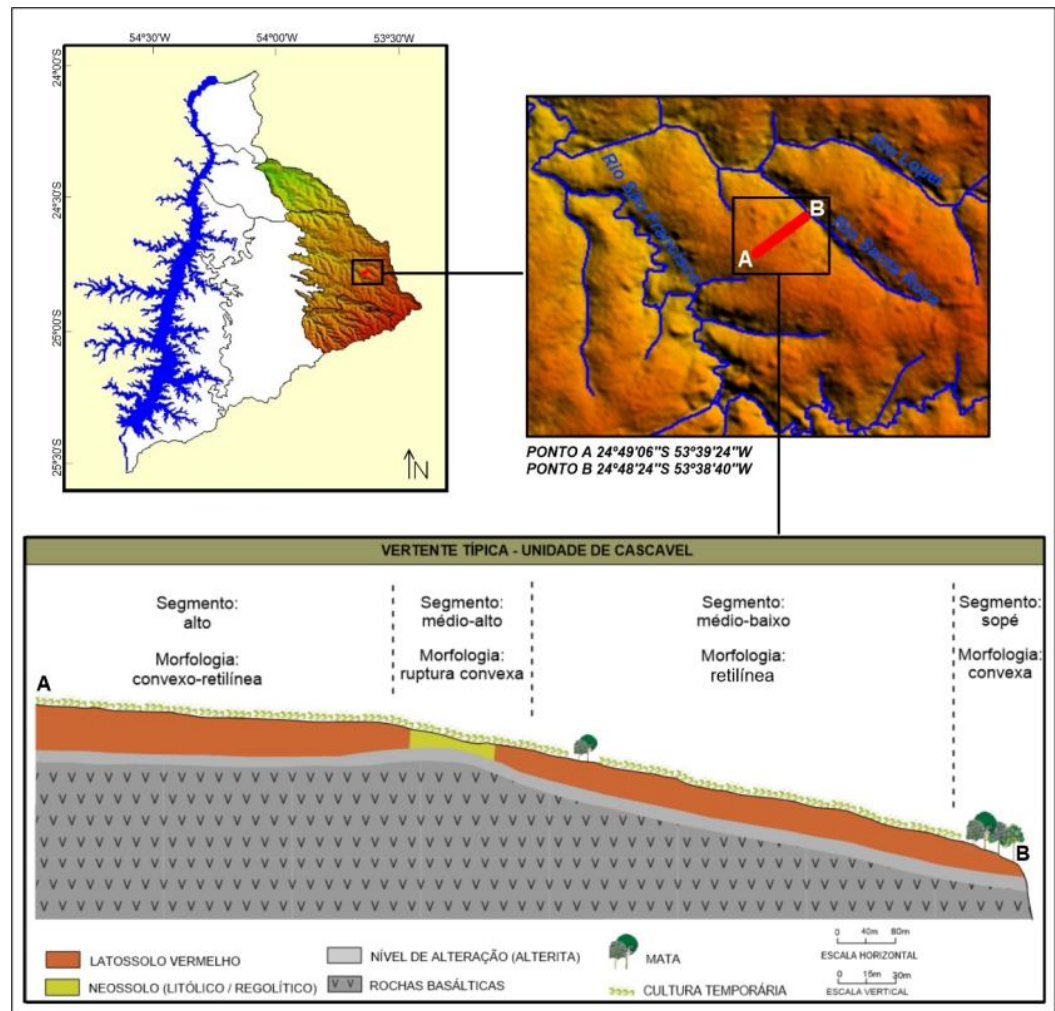

Figura 07. Vertentes características da unidade de Cascavel.

A cobertura pedológica nessa unidade apresenta basicamente dois sistemas dominantes:

- um composto por Latossolos Vermelhos desde o topo até a baixa vertente, apresentando, contudo, uma estreita faixa de Neossolos Regolíticos e Cambissolos Háplicos (que não aparecem nos mapas pedológicos em virtude da escala) junto às rupturas de declive, mesmo quando estas não são acentuadas. Este sistema domina nos setores mais altos da bacia envolvendo as cabeceiras de drenagem; 
- um outro sistema composto por Latossolos Vermelhos, que se entendem do topo até a média e frequentemente até a média-baixa vertente quando passam para Nitossolos Vermelhos. Ocorrem ao longo das vertentes que apresentam um aumento de declividade no seu terço inferior. Esse tipo é cada vez mais frequente à medida que se aproxima dos setores médios dos cursos d'água.

Dada a originalidade do arranjo, forma e sistema pedológico, escolheu-se como vertente característica para este estudo, aquela que ocorre nos setores mais elevados, localizada na subunidade de Toledo, próximo às cabeceiras. A vertente típica dessa unidade (Figura 8) é então representada pelo domínio do Latossolo, com a ocorrência localizada de Neossolo na média-alta vertente.

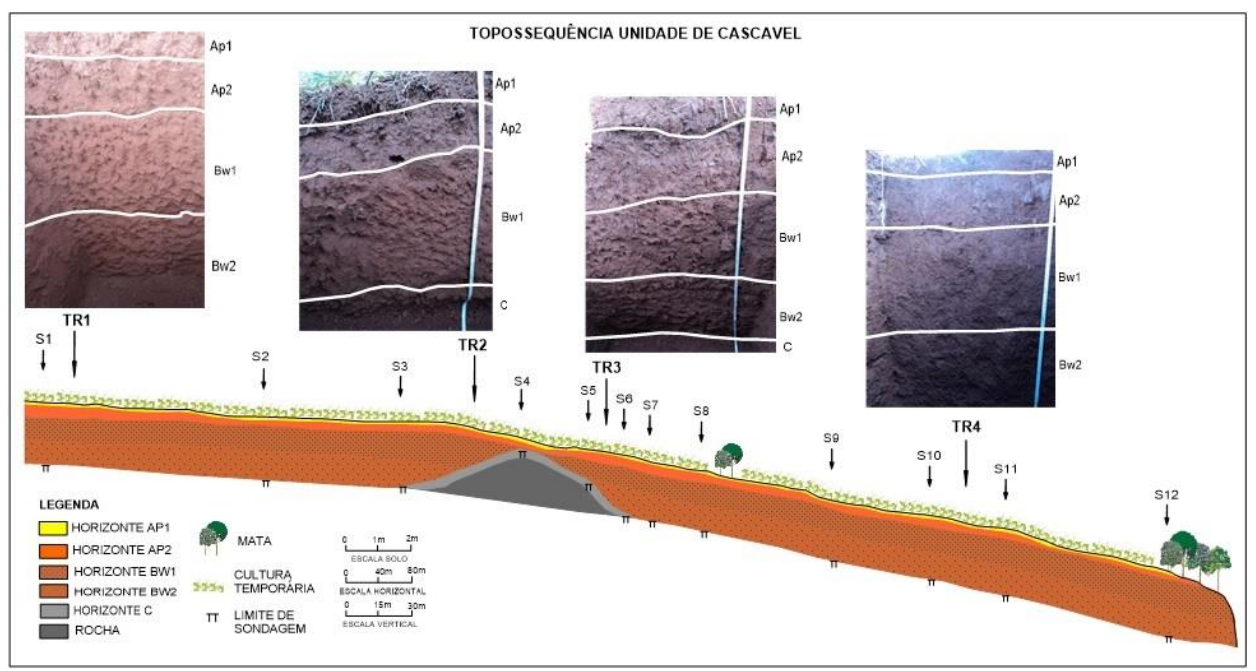

Figura 08. Topossequência da unidade de Cascavel.

Tanto a montante quanto a jusante da ruptura verifica-se a presença do Latossolo, com horizonte $\mathrm{Bw}$ superior a 2 metros de profundidade. Entretanto, junto à ruptura, entre a sondagens 3 e 6 , se observa o estreitamento e desaparecimento do $\mathrm{Bw}$ e o aparecimento e espessamento do horizonte $\mathrm{C}$, evidenciando que além de uma ruptura de declividade (pouco marcada) ocorre aí uma zona de transformação, com o surgimento localizado de Neossolo Regolítico. Desenha-se, neste caso, uma "descontinuidade" no sistema pedológico, que trunca os segmentos a montante e a jusante dela.

A ocorrência de rocha a pequena profundidade no setor de média-alta vertente introduz nesse sistema pedológico uma zona de transformação lateral. As transformações laterais estão relacionadas principalmente ao aparecimento e espessamento do $\mathrm{Bw}$. No setor em que o bloco rochoso está mais próximo à superfície, a cobertura pedológica é estreita e constituída apenas pelo horizonte Ap justaposto a um horizonte C, também 
relativamente estreito, configurando aí um Neossolo Regolítico. Entretanto, lateralmente, já aparece um horizonte B que atinge a espessura de $50 \mathrm{~cm}$ (limite mínimo exigido para o Bw, de acordo com EMBRAPA (2013), a cerca de 60 metros (TR2) a montante do bloco rochoso e a menos de 50 metros (TR3) a jusante, apresentando, portanto, os atributos morfológicos que permitem defini-lo como um Bw. Desse modo, apenas em uma faixa estreita de alguns metros, ladeando o bloco rochoso, o horizonte B apresenta menos de $50 \mathrm{~cm}$ mantendo, contudo, todos os outros atributos do Bw.

Assim o sistema pedológico que ocorre ao longo dessa vertente característica, apesar da forma convexo-retilínea, com uma ruptura de declividade pouco marcada na passagem do segmento convexo para o retilíneo, é constituído de fato por Latossolo Vermelho Eutroférrico - Neossolo Regolítico Eutrófico - Latossolo Vermelho Eutroférrico.

Em geral o domínio da topografia suave ondulada, dos solos profundos e altamente intemperizados, favorecem a agricultura temporária (soja, milho, trigo, aveia), aqui praticada de modo intensivo e altamente mecanizado, associada a propriedades médias e grandes distribuídas na unidade de Cascavel.

No interior dessa grande unidade (Cascavel) ocorrem pequenos setores onde as vertentes são mais curtas, as declividades mais acentuadas e os solos de caráter Litólico e/ou Regolítico tem maior expressão espacial. Nessas áreas aparecem de modo mais expressivo as pastagens ou manchas de vegetação florestal, intercaladas às culturas temporárias.

\section{Unidade de São Francisco: as vertentes características e os sistemas pedológicos no setor intermediário}

A unidade de São Francisco está localizada na porção central da unidade hidrográfica entre as altitudes de 200 e 700 metros e abrange especialmente os setores médios dos cursos de água. Compõe a unidade de maior dissecação da bacia, onde predominam declividades entre 12 e $20 \%$, solos rasos, predominantemente ocupados por pastagens, em associação com cultivos agrícolas e vegetação florestal.

Na unidade de São Francisco, do ponto de vista geomorfológico, predomina um relevo de aspecto amorreado, onde os topos são estreitos, e os vales são encaixados. As vertentes geralmente apresentam formas compostas por segmentos alternando segmentos convexos, côncavos e retilíneos, marcadas por rupturas de declividade acentuadas, onde se distinguem patamares (Figura 09).

Nessa unidade, assim como nas demais, a cobertura pedológica reflete as variações das formas e das declividades. Nos setores de vertentes compostos por rupturas, seguidas de formas convexas e segmentos retilíneos com declividades de 12 a $20 \%$ e de 20 a 30\%, é comum a presença dos Neossolos Litólicos e/ou Regolíticos. Aí a erosão e o transporte de material ocorrem de forma mais intensa, devido ao domínio do escoamento superficial. Já 
nos setores de vertentes compostos por formas côncavas, associadas a segmentos retilíneos com declividades entre 6-12\%, verifica-se a presença dos Nitossolos.

Nesses casos, quando as formas se apresentam ligeiramente côncavas, ocorre o acúmulo de material coluvial, advindo de áreas de maior inclinação, a montante. $\mathrm{O}$ acúmulo de material, as fracas declividades e a circulação hídrica vertical e lateral que se estabelece geram condições para um maior desenvolvimento pedogenético, marcado pela ocorrência localizada dos Nitossolos.

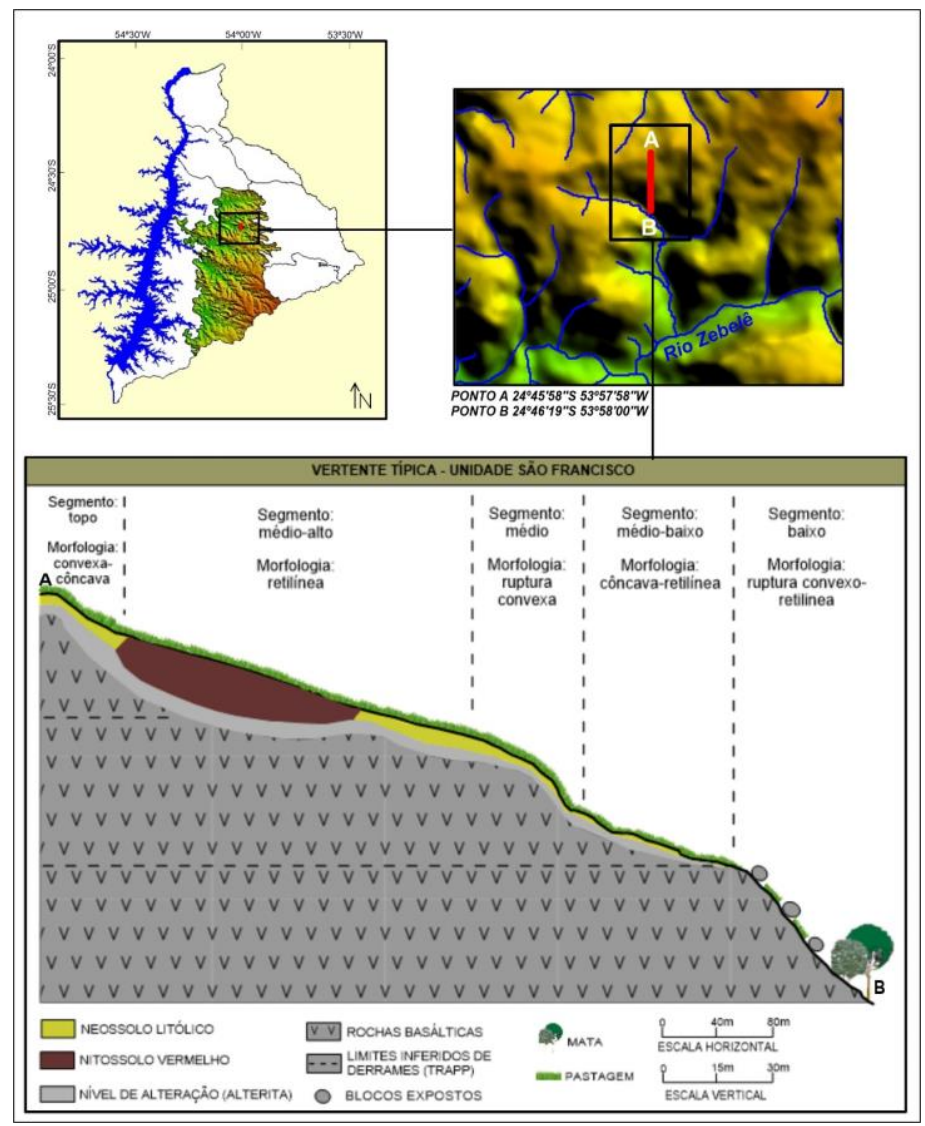

Figura 09. Vertentes Características da Unidade de São Francisco

Essas associações morfopedológicas, podem ser observadas na representação da topossequência da unidade de São Francisco (Figura 10), marcada por rupturas e patamares que representam o modelo de vertente característica e o sistema pedológico dominante na maior parte da unidade, composto por Neossolo Litólico e/ou Regolítico e Nitossolo Vermelho. 


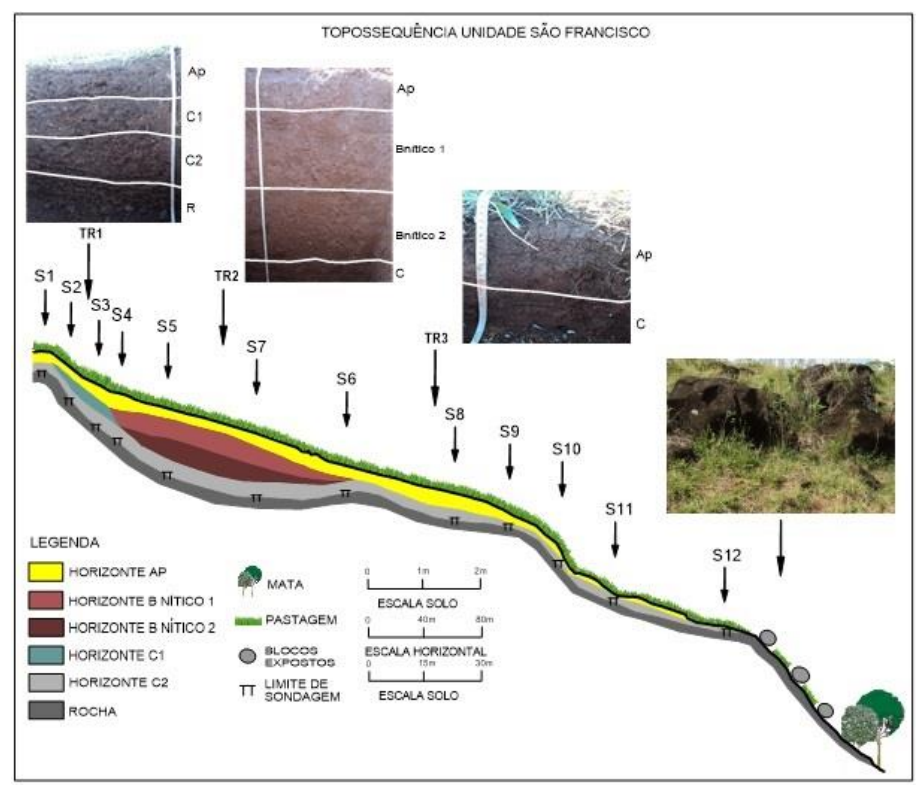

Figura 10. Topossequência da Unidade de São Francisco.

A vertente típica de São Francisco exibe no segmento de topo, convexo e curto, o domínio do Neossolo Regolítico. O setor médio-alto apresenta uma forma retilínea, mais levemente inclinada, recoberta principalmente pelo Nitossolo Vermelho. Pelas observações realizadas em campo, originalmente esse setor apresentava uma forma côncava que foi preenchida por material coluvial de remanejamento local, gerando condições para um maior desenvolvimento pedogenético, resultando na formação do Nitossolo. Sequencialmente apresentam-se duas rupturas muito marcadas seguidas de segmentos fortemente inclinados no setor médio-baixo e baixo. No primeiro setor verifica-se a ocorrência do Neossolo Litólico e, a jusante, o afloramento rochoso em razão do aumento de declividade. Longitudinalmente a vertente se estende por 480 metros e tem um desnível de 90 metros.

As rupturas e patamares, identificadas nos setores de alta, média e baixa encosta, são de caráter estrutural, relacionados à sequência dos derrames basálticos. Nas rupturas se constata a presença de basalto vesicular/amigdaloidal, característico de topo de derrames. Esses aspectos são preponderantes nas vertentes características dessa unidade, geralmente compostas por três rupturas e seccionadas em patamares.

A unidade de São Francisco é a região onde a pastagem e a mata nativa apresentam maior representatividade ao longo de toda a bacia do Paraná 3. Essa realidade encontra-se intimamente relacionada às limitações topográficas e pedológicas (altas declividades e solos predominantemente rasos). 


\section{Unidade de Foz do Iguaçu: as vertentes características e os sistemas pedológicos no baixo setor}

A unidade de Foz do Iguaçu localiza-se no extremo Oeste da bacia, às margens do lago de Itaipu. Compreende o setor mais baixo, com altitudes que variam de 100 a 400 metros, particularmente formado por colinas médias a amplas (relevo suave ondulado), com declividades inferiores a 6\%. A cobertura pedológica é representada pelo sistema Latossolo Vermelho-Nitossolo Vermelho. Localmente, às margens do rio Paraná ou ainda em setores de planície ocorrem manchas de Argissolo Vermelho e de Gleissolo Háplico.

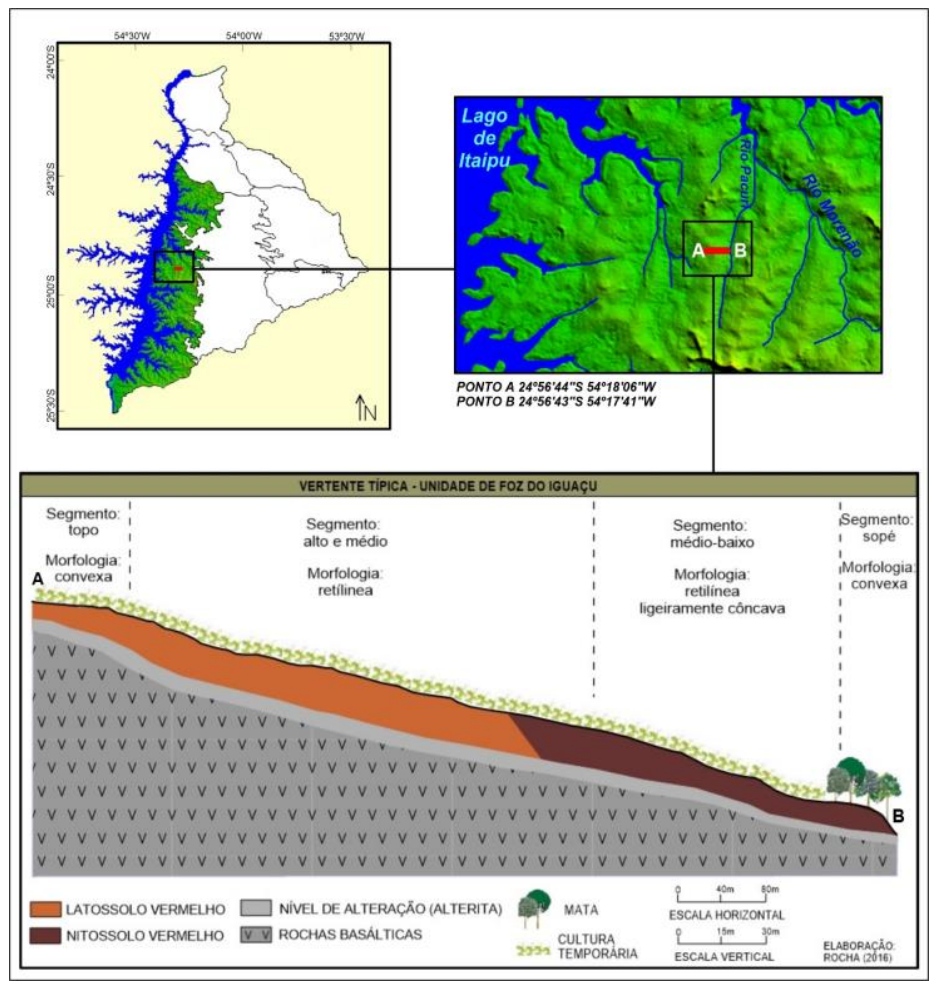

Figura 11. Vertentes Características da Unidade de Foz do Iguaçu

Na unidade, predominam colinas de baixa dissecação. Dos topos ligeiramente convexos e achatados partem as vertentes que são dominantemente retilíneas apresentando, contudo, uma suave ruptura côncava na base - junção com o fundo de vale. Os vales são geralmente abertos e os fundos são planos (Figura 11). 
A vertente característica da unidade de Foz do Iguaçu é caracterizada por morfologia típica convexa-retilínea, com 720 metros de comprimento e um desnível de 60 metros do topo ao sopé da vertente.

Ao longo da vertente estudada, do topo até a média-baixa encosta, a cobertura pedológica exibe uma sequência de horizontes Ap1, Ap2, BA e Bw. A partir da média baixa-encosta, em direção ao sopé, verifica-se a presença de um horizonte B nítico, que aí se inicia e se espessa para jusante (Figura 12).

Nesse setor, os topos convexos e achatados são mais curtos, comparados ao setor superior da unidade hidrográfica. Cabe destacar que a cobertura pedológica dos segmentos de topo, apesar de formada por Latossolos, apresenta menor espessura, tendo em vista que o substrato rochoso muitas vezes ocorre entre 1,5 a 2 metros da superfície.

O sistema pedológico que domina essa vertente característica é constituído pelo Latossolo Vermelho Eutroférrico a montante e o Nitossolo Vermelho Eutroférrico a jusante. Esta organização da cobertura pedológica caracteriza o sistema de maior representatividade espacial, não só ao longo da unidade de Foz do Iguaçu, mas ao longo de todo o setor rebaixado da bacia do Paraná 3.

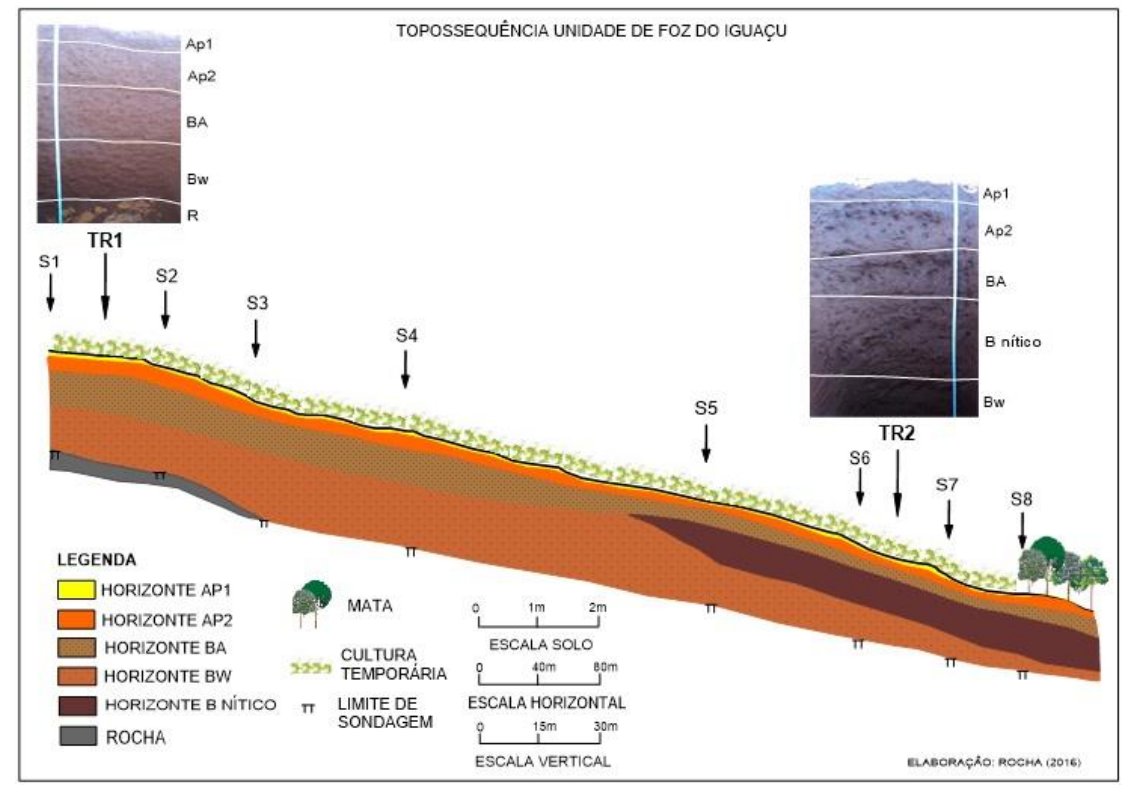

Figura 12. Topossequência da Unidade de Foz do Iguaçu.

Em geral o uso da terra nessa porção da unidade hidrográfica é predominantemente agrícola, resultante do aproveitamento da topografia caracterizada pelas fracas declividades e dos solos favoráveis aos cultivos temporários mecanizados. 
Verifica-se ainda um relevante papel da piscicultura associada ao potencial hídrico disponível em razão da formação do lago de Itaipu na região.

\section{Considerações finais}

A identificação e análise detalhada das vertentes características das principais unidades de paisagem da bacia do Paraná 3, permitiu identificar e compreender a organização dos sistemas pedológicos a elas associados. Constatou-se que as diferenças em termos de declividade, comprimento, ausência ou presença de rupturas de declive, assim como os graus de convexidade e concavidade das vertentes, levam ao desenvolvimento e organização diferenciados da cobertura pedológica, capazes de caracterizar, do ponto de vista morfopedológico, essas unidades de paisagem.

Por outro lado, o detalhamento do estudo dessas vertentes por meio de análises físico-hídricas, possibilitarão reconhecer, além das características morfopedológicas aqui apresentadas, como funcionam e se comportam frente à diferentes processos (infiltração, escoamento, erosão) e sobretudo solicitações antrópicas.

Desse modo, os estudos detalhados das vertentes características e dos sistemas pedológicos dominantes nos setores de alto, médio e baixo da unidade hidrográfica do Paraná 3, poderão subsidiar o conhecimento da estrutura e dinâmica das unidades de paisagem, contribuindo para vários outros estudos como, por exemplo, a identificação e o mapeamento das fragilidades e potencialidades ambientais, principalmente aqueles referentes à capacidade de uso do solo.

\section{Referências}

BADE, M. R. Definição e Caracterização das Unidades de Paisagem das Bacias Hidrográficas do Paraná III (Brasil/Paraguai). Universidade Estadual do Oeste do Paraná, campus de Marechal Cândido Rondon - PR, 2014. 113 p. (Dissertação de Mestrado).

BHERING, S.B.; SANTOS, H.G. Mapa de solos do Estado do Paraná. Legenda atualizada. Rio de Janeiro, Embrapa Florestas/Embrapa Solos/Instituto Agronômico do Paraná, 2008.

BOULET, R.; CHAUVEL, A.; HUMBEL, F. X.; LUCAS, Y. Analyse structurale et pédologie I. Prise em compte do l'organisation bidimenionnelle de la couverture pédologique: lês études de toposéquences et leurs princinale principaux apports à la conaissance dês sols. Cah ORSTOM, ser. Pédol., vol. XIX, n 4, p. 309-322, 1982.

CAMPOS, M. C. C; RIBEIRO, M. R.; SOUZA JÚNIOR, V. S.; RIBEIRO FILHO, M. R.; COSTA, E. U. C. Segmentos de vertente e atributos do solo de uma toposseqüência na região de Manicoré, Amazonas. Revista Ciência Agronômica, v. 41, n. 4, p. 501-510, 2010.

CASTRO, S. S. Sistema de transformação pedológica em Marilia, SP: B latossólicos e B texturais. (Tese de Doutorado). Universidade de São Paulo, Faculdade de Filosofia, Letras e Ciências Humanas, São Paulo. 1989. 
CASTRO, S. S; SALOMÃO, F. X. T; Compartimentação morfopedológica e sua aplicação: Considerações metodológicas. GEOUSP, Espaço e tempo, n. 7, p. 27-37, 2000.

EMPRESA BRASILEIRA DE PESQUISA AGROPECUÁRIA. Sistema brasileiro de classificação de solos.3.ed. Brasília: EMBRAPA, 2013.

FERNANDES BARROS, O. N. Análise estrutural e cartografia detalhada dos solos em Marilia, SP: ensaio metodológico. Universidade de São Paulo, Faculdade de Filosofia, Letras e Ciências Humanas, São Paulo. 1986. (Dissertação de Mestrado).

MANFREDINI, S.; FURIAN DIAS, S. M.; QUEIROZ NETO, J. P.; OLIVEIRA, D.; FERREIRA, R. D. P. Técnicas em Pedologia. In: VENTURI, L. B. (org) Praticando Geografia: técnicas de campo e laboratório em geografia e análise ambiental. São Paulo: Oficina de textos, 2005, p. 85-98.

MANOSSO, F. C.; NÓBREGA, M. T. A estrutura geoecológica da paisagem como subsídio a análise geoambiental no município de Apucarana-PR. Revista Geografar (UFPR), v. 3, p. 86-116, 2009.

MINEROPAR (SERVIÇO GEOLÓGICO DO PARANÁ). Mapas Geológicos 1:250.000 Disponível em: http://www.mineropar.pr.gov.br/. Acesso em: 10 de janeiro 2015.

MONTEIRO, C. A. F. Geossistemas: a história de uma procura. São Paulo: Contexto, 2001.

MOTTA, P. E. F.; CARVALHO FILHO A.; KER, J. C.; PEREIRA, N. R.; CARVALHO JUNIOR, W.; BLANCANEAUXET, P. Relações solo-superfície geomórfica e evolução da paisagem em uma área do Planalto Central Brasileiro. Pesquisa Agropecuária Brasileira, Brasília, v. 37 , n. 6 , p. $869-878,2002$.

PAVAN, M. A.; BLOCH, M. de F.; ZEMPULSKI, H. da C.; MIYAZAWA, M.; ZOCOLER, D. C. Manual de análise química do solo e controle de qualidade. Londrina, IAPAR, 1992.

QUEIROZ NETO, J. P. Análise estrutural da cobertura pedológica: uma experiência de ensino e pesquisa. Revista do Departamento de Geografia, São Paulo. v.15, p 77 - 90. 2002.

RIBEIRO, J. C.; SALOMÃO, F. X. de T. Abordagem morfopedológica aplicada ao diagnóstico e prevenção de processos erosivos na bacia hidrográfica do alto rio da casca, MT. Revista Geociências, São Paulo, v. 22, n. 1, p. 83-95, 2003.

RUELLAN A. Contribuição de pesquisas em zona tropical ao desenvolvimento da Ciência do Solo. In: Anais...Congresso Brasileiro de Ciência do Solo, 21, Campinas, São Paulo, Sociedade Brasileira de Ciência do Solo, p. 67-74. 1988.

RUELLAN, A.; DOSSO, M. Regards sur le sol. Paris: Les Éditions Foucher, 1993. 
SALOMÃO, F. X. T. Processos erosivos lineares em Bauru (SP): regionalização e cartografia aplicada ao controle preventivo urbano e rural. Universidade de São Paulo, Faculdade de Filosofia, Letras e Ciências Humanas, São Paulo. 1994. (Tese de Doutorado).

SOUBIÉS F., CHAUVEL A. Présentation de quelques systèmes de sols observes au Brésil. Cah. ORSTOM. n. 4, 237-251, 1984.

VIDAL-TORRADO, P; LEPSCH, I. F.; CASTRO, S. S. Conceitos e aplicações das relações Pedologia-Geomorfologia em regiões tropicais úmidas. Tópicos em Ciência do Solo. Viçosa, MG: Sociedade Brasileira de Ciência do Solo, v. 4, p. 145-192, 2005.

YOUNG, A. Slopes, London: Longman. 1972.

\author{
Anderson Sandro da Rocha \\ Doutor em Geografia pela Universidade Estadual de Maringá. Atualmente é \\ professor da Universidade Tecnológica Federal do Paraná. \\ Av. Brasil, 4232, CEP: 85884-000, Medianeira - PR \\ E-mail: andersonrocha@utfpr.edu.br \\ Maria Teresa de Nóbrega \\ Doutora em Geociências pela Universidade de São Paulo. Atualmente é professora \\ do Programa de Pós-Graduação em Geografia da Universidade Estadual de \\ Maringá. \\ Av. Colombo, 5790, CEP: 87020-900, Maringá - PR \\ E-mail: mtnobrega@uol.com.br \\ José Edézio da Cunha \\ Doutor em Geografia Física pela Universidade de São Paulo. Atualmente é \\ professor da Universidade Estadual do Oeste do Paraná, nos cursos de graduação e \\ Pós-Graduação em Geografia. \\ Rua Pernambuco, 1777, CEP: 85960-000, Marechal Cândido Rondon - PR \\ E-mail: edeziocunha@hotmail.com
}

Recebido para publicação em novembro de 2016 Aprovado para publicação em agosto de 2017 